\title{
Optimization Conditions of UV-C Radiation Combined with Ultrasound-Assisted Extraction of Cherry Tomato (Lycopersicon esculentum) Lycopene Extract
}

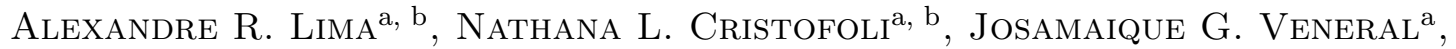 \\ Alcilene R. M. Fritz ${ }^{\mathrm{a}}$, AND Margarida C. Vieira ${ }^{\mathrm{b}, \mathrm{c}^{*}}$ \\ ${ }^{a}$ Department of Chemical Engineering and Food Engineering (EQA), Federal University of Santa Catarina, SC \\ Cidade Universitária, Trindade, 88040970, Florianópolis (SC), Brazil \\ b Department of Food Engineering, Institute of Engineering, University of Algarve, Faro, Portugal \\ ${ }^{\mathrm{c}}$ MeditBio-Centre for Mediterranean Bioresources and Food, Faculty of Sciences and Technology, University of \\ Algarve, Faro, Portugal \\ ${ }^{*}$ Corresponding author \\ mvieira@ualg.pt \\ TEL: +351289800100
}

Received: 19 July 2018; Published online: 18 October 2019

\begin{abstract}
The aim of this work was to study the effect of UV-C radiation on ultrasound assisted extraction (UAE) of cherry tomato bioactive compounds. Cherry tomatoes were exposed to two UV-C radiation doses $\left(0.5\right.$ and $\left.1.0 \mathrm{~J} \mathrm{~cm}^{-2}\right)$ and stored at $20 \pm 0.5{ }^{\circ} \mathrm{C}$ for 7 days. Next, they were lyophilized, and the bioactive compounds were extracted by UAE at $20 \mathrm{KHz}$. To evaluate the effectiveness of the extraction process of the bioactive compounds, a CCRD (central composite rotational design) was used together with RSM (response surface methodology), for extraction times from 4 to 12 minutes and concentrations ( $\mathrm{g}$ of lyophilized product / $\mathrm{L}$ of ethanol) of 1:10, 1:20 and 1:30. The extracts obtained from the irradiated tomatoes presented 5.8 times more lycopene content than the controls and higher antioxidant activity was obtained for 4 and $8 \mathrm{~min}$, in the concentrations 1:10 and 1:20 (m $\mathrm{v}^{-1}$ ). Through numerical model optimization, optimal extraction conditions were obtained. The results demonstrated that by previously irradiating tomatoes with UV-C light, the UAE yielded considerably higher amounts of lycopene and other bioactives.
\end{abstract}

Keywords: UV-C radiation; Cherry tomato, Ultrasound extraction; Lycopene

\section{Introduction}

Tomatoes are at the top of the list of fruits with high antioxidant power due to the presence of compounds like lycopene, flavonoids, phenolics and vitamins responsible for their antioxidant capacity (Artes, Gomez, Aguayo, Escalona, \& Artes-Hernandez, 2009). Tomato's major carotenoid is lycopene which is responsible for the red color on ripe tomatoes and tomato products (Honda et al., 2017). In addition, consump- tion of lycopene is often associated with the prevention of some diseases, such as prostate cancer (Di Mascio, Kaiser, \& Sies, 1989). Shi and Le Maguer (2000), showed that tomato, because of its innumerable evidence on cancer risk reduction, has assumed its functional food status. UV-C radiation and ultrasounds are often applied to food to replace thermal treatments (or decrease their severity) providing products with better physical and chemical attributes. UV-C 
$66 \mid$ Lima et al.

light application has benefical impacts in several quality parameters of fresh fruits and vegetables. UV-C light reduces maturation rate, thus improves firmness, increases pigmentation levels and shelf life (Artes et al., 2009). UV- C light is used to reduce microbial load on fruits and vegetables and others food products (Karg et al., 2008; Stevens et al., 1999). Several authors reported that after UV-C irradiation of fruits and vegetables the concentration of antioxidant compounds increased (Liu, Hu, Zhao, \& Song, 2012; Majeed et al., 2016).

As well as UV-C light, ultrasound is a good technology for food preservation. High intensity ultrasound assisted extraction (UAE) is an important process that is used to extract bioactive compounds from fruits and vegetables (Riera et al., 2004). UAE does not have operational toxicity and uses low amount of organic solvents (Feng, Luo, Tao, \& Chen, 2015). In addition, its low operating temperatures and high power probes that generate ultrasound are versatile and diversified for application in food industry (Awad, Moharram, Shaltout, Asker, \& Youssef, 2012). Ultrasound can stimulate diverse processes of extraction because of propagation of high-level pressure waves producing cavitation phenomenon that causes disturbance in plants' cell walls. Throught violent implosions, cavitation promotes an acceleration process of diffusion and increase of mass transfer through the surface fragmentation of the solid matrix (Chemat et al., 2017). Therefore, there is increasing erosion and surface fragmentation followed by increased of heat and mass transfer, resulting in an easier release of bioactive compounds which in turn increases the extracted yield quickly and efficiently (Chemat, Zill-e-Huma, \& Khan, 2011; Vilkhu, Mawson, Simons, \& Bates, 2008).

The main objective of the present study was to investigate the effect of UV-C radiation on the ultrasound-assisted extraction of bioactive compounds from cherry tomato.

\section{Materials and Methods}

\subsection{Cherry tomato sample}

Tomatoes were selected from those which had uniform size (diameter 20-30 mm), red color, about 5.5 Brix of total soluble solids, and physical integrity. Samples were washed under running water and sanitized in a $200 \mathrm{ppm}$ chlorine solution for 15 minutes. After that, the fruits were separated into three groups: UV1-C and UV2-C light treatments, plus one control group (C).

\section{$2.2 \quad$ UV-C light treatments and storage}

UV-C light treatments were carried out with ten UV germicidal lamps (2G11-OSRAM, Munich, Germany) that emitted light at $254 \mathrm{~nm}$.

Tomatoes were exposed to radiation doses of 0.5 $\mathrm{J} \mathrm{cm}^{-2} \mathrm{UV} 1$ and $1.0 \mathrm{~J} \mathrm{~cm}^{-2}$. A portable radiometer (UV-Integrator - Model UV int 150+ Integration Technology Ltd., United Kingdom) was used to measure the radiation doses. The irradiated intensity was $1.5 \mathrm{~W} \mathrm{~m}^{-2}$ for the UV1 group and $3 \mathrm{~W} \mathrm{~m}^{-2}$ for the UV2 group. The irradiated cherry tomatoes were rotated $180^{\circ}$ horizontally and exposed to the same dose for 60 $\mathrm{min} /$ side on the surface. The three groups of samples (UV1-treated, UV2-treated, and control (C)) were distributed and stored in rigid plastic trays $(18.0 \times 12.5 \times 8.0 \mathrm{~cm})$ and stored at $20^{\circ} \mathrm{C} \pm$ $0.5^{\circ} \mathrm{C}$ for 7 days. Then, tomatoes without seeds were lyophilized (Freeze dryer - model L101- Liotop, São Paulo, Brazil). Tomato powder was obtained from dried samples ground in a knife grinder.

\subsection{Ultrasound-assisted extraction of the lycopene from cherry powder tomatoes}

An ultrasonic tip sonicator (QR500 - ECO SONICS, São Paulo, Brazil) was immersed in a beaker $(200 \mathrm{~mL})$ containing $5 \mathrm{~g}$ of sample and 50, 100 and $150 \mathrm{~mL}$ of ethanol as extraction solvent having concentrations of 1:10, 1:20 and 1:30 in $\mathrm{m}$ $\mathrm{V}^{-1}$, respectively.

IJFS | October 2019 | Volume 8 pages 65-80 
Power was set at $400 \mathrm{~W}$ (RMS), with an ultrasonic frequency of $20 \mathrm{kHz}$. The temperature was controlled and maintained at $20^{\circ} \mathrm{C}$ using an ice bath. The extraction times selected were 4,8 and 12 minutes. After the extraction, the extracts were filtered under vacuum, and residual solvent was removed in a vacuum rotary evaporator (Model 802-FISATOM Ltda., São Paulo, Brazil). The extracts were collected in amber glass and stored at $-18^{\circ} \mathrm{C}$ until further analyzes were performed.

\subsection{Experimental design and statistical analysis}

Response surface methodology (RSM) using a central composite rotational design (CCRD) and with a reduced cubic model (Design-Expert trial version 11) was employed to determine the best levels of the three independent variables $\left(\mathrm{X}_{U V}\right.$, $\mathrm{UV}-\mathrm{C}$ radiation dose, $\mathrm{X}_{E T}$, extraction time, $\mathrm{X}_{S C}$, extraction solvent concentration). Three levels $(-1.0,0,+1.0)$ were used to evaluate the optimum combinations regarding four responses (lycopene content (LC), total phenolic compounds (TPC), trolox equivalent antioxidant capacity (TEAC) and (DPPH) radical scavenging activity).

The analysis of variance (ANOVA) and Tukey test were used to determine the statistical significance between lycopene content, antioxidant activity, and TPC values with a $95 \%$ confidence level.

UV-C radiation varied between 0.5 and $1.0 \mathrm{~J}$ $\mathrm{cm}^{-2}$ and the control (no-radiation), the ratio of extraction solvent for the solid matter ranged from 50 to $150 \mathrm{~mL}$, extraction time from 4 to $12 \mathrm{~min}$. All the ranges for the parameters were selected based on preliminary experimental work and literature. The range of independent variables and their levels were depicted in Table 1.

The variation of LC, TPC, TEAC and DPPH radical scavenging activity related to the three variables $\mathrm{X}_{U V C}, \mathrm{X}_{E T}$ and $\mathrm{X}_{S C}$ were evaluated using a polynomial second degree model given by the following equation:

$$
Y=\beta_{0}+\sum \beta_{i} X_{i}+\sum \beta_{i j} X_{i} X_{j}+\sum \beta_{i i} X_{i}^{2}
$$

Where $\mathrm{Y}$ is the predicted response, $\beta_{0}$ is the fixed response at central point, $\beta_{i}, \beta_{i i}$ and $\beta_{i j}$ are the linear, quadratic and interaction coefficients, respectively. $\mathrm{X}_{i}$ and $\mathrm{X}_{j}$ are the levels of the independent variables.

\subsection{Lycopene content (LC)}

Lycopene content of the cherry tomatoes extracts (C, UV1 and UV2) was quantified by spectrophotometry according to methodology proposed by Fish, Perkins-Veazie, and Collins (2002) with modifications. The absorbance was measured at $503 \mathrm{~nm}$ with a spectrophotometer (Hitachi UV/Vis U-2000 - Hitachi Ltd., Tokyo, Japan). The lycopene content of samples was estimated using $L C=\left(\begin{array}{lll}A_{503} & x & 31.2\end{array}\right) / g_{\text {extract }}$ (where 31.2 $\mathrm{g} \mathrm{cm}^{-1}$ is the extinction coefficient for lycopene in hexane) and expressed as $\mathrm{mg} \mathrm{g}^{-1}$ (Fish et al., 2002).

\section{Total phenolic compounds (TPC)}

The total phenolic content was quantifield using the Folin-Ciocalteu method described by Singleton, Orthofer, and Lamuela-Raventos (1999). The absorbance was measured at $765 \mathrm{~nm}$ in spectrophometer. The TPC was calculated using a standard curve prepared previously with gallic acid as a standard compound. The assays were performed in triplicates and the average results were expressed as milligrams of gallic acid equivalent (GAE) per gram extract $\left(\mathrm{mg} \mathrm{GAE} \mathrm{g}^{-1}\right) \pm$ standard deviation.

\subsection{Antioxidant activity (AA)}

\section{Trolox equivalent antioxidant capacity assay (TEAC)}

TEAC assay was employed to measure AA capacity based on the procedure described by Re et al. (1999). The absorbance was measured at $734 \mathrm{~nm}$ in spectrophotometer. Results were expressed as TEAC values $\left(\mu \mathrm{g}\right.$ Trolox $\left.\mathrm{g}^{-1}\right)$. In order to find TEAC values, a separate concentration response curve for standard Trolox solutions was prepared and results were presented by average \pm standard deviation from triplicate assays. 
68 Lima et al.

Table 1: Independent variables and their respective levels

\begin{tabular}{ccccc}
\hline \multirow{2}{*}{ Independent variable } & \multirow{2}{*}{ Symbol } & \multicolumn{3}{c}{ Level } \\
\cline { 3 - 5 } & & -1 & 0 & 1 \\
\hline UV-C radiation $\left(\mathrm{J} / \mathrm{cm}^{2}\right)$ & $\mathrm{X}_{U V C}$ & $0^{*}$ & 0.5 & 1.0 \\
Extraction time $(\mathrm{min})$ & $\mathrm{X}_{E T}$ & 4 & 8 & 12 \\
Solvent concentration $(\mathrm{mL})$ & $\mathrm{X}_{S C}$ & 50 & 100 & 150 \\
\hline
\end{tabular}

\section{Free radical scavenging activity (DPPH)}

The free radical scavenging of cherry tomato extracts was evaluated using the (DPPH) method according to the procedure reported by Mensor et al. (2001). The absorbance values were measured in spectrophotometer at $517 \mathrm{~nm}$ and converted into percentage of antioxidant activity (AA\%). This activity was also presented as the effective concentration at 50\% (EC50), which is the solution concentration required to give $50 \%$ decrease in the absorbance of the test solution compared to a blank solution and expressed in $\mu \mathrm{g}_{\text {extract }} \mathrm{mL}^{-1}$. The $\mathrm{EC}_{50}$ values were calculated by linear regression from the curves of the AA\% obtained for all extract concentrations. The $\mathrm{AA} \%$ and $\mathrm{EC}_{50}$ for all extracts were obtained by taking the average of triplicate assays.

\section{Results and Discussions}

\subsection{Fit of models and obtained responses}

The results for LC, TPC, TEAC, DPPH radical scavenging activity analysis are presented in Table 2 .

Experimental variables, UV-C radiation dose, extraction time, and solid/liquid ratio (solvent concentration) were the determinants of the combination of UV-C radiation and UAE technologies.

The results of ANOVA showed that the models were significant with good determination coefficients $\left(\mathrm{R}^{2}\right)$ for lycopene content, TPC, TEAC and $\mathrm{DPPH}$ radical scavenging activity, implying that the correlation between response and in- dependent variables was satisfactory $(\mathrm{p}>0.05)$. In addition, the $\mathrm{F}$-values and $\mathrm{p}$-values were obtained for the reduced cubic model (Table 3). Thus, values of $\mathrm{R}^{2}$ closer to 1.0 mean higher accuracy of the model.

The high values for predicted and adjusted determination coefficients also illustrate the model suitability in relation to the experimental data (Badwaik, Prasad, \& C. Deka, 2012). Adequance Precision (Table 3) measures the signal to noise ratio and a ratio greater than 4 is desirable. By observing the values (Table 3), all are higher than the desired minimum value and it is possible to state that the proposed models can be used to navigate the design space.

\subsection{Checking assumptions with residual plots}

Through the use of residual plots, it is possible to investigate the normality, constant variation and linearity hypothesis of the simple linear regression model. If these assumptions are true, then the observed residual using the equation $e_{i}$ $=y_{i}-\hat{y}_{1}$ (where, $\mathrm{e}_{i}$ : observed sample residue; $y_{i}$ : y-value observed; $\hat{y}_{1}: \mathrm{y}$-value predicted) should behave in a similar fashion.

Therefore, it is possible to observe the error terms of distribution normality, constant variance along $\mathrm{X}$ and the values independence of $\mathrm{X}$, through the analysis of the graphs residual vs run (Fig. 1D, 2D, 3D and 4D).

In the interval between -3.6 and 3.6 , it can be observed that for any of the dependent variables, the residual plots contradict the linearity assumption, behaving in a nonlinear way with a random distribution throughout the space of $\mathrm{X}$ axis. These residual plots prove that the assump- 
Ultrasound-assisted extraction of lycopene extracts from UV-C irradiated cherry tomatoes |69

Table 2: Values of response variables (LC, TPC, TEAC and DPPH) obtained at treatment conditions used in experimental design by RSM

\begin{tabular}{|c|c|c|c|c|c|c|}
\hline \multirow{2}{*}{$\begin{array}{l}\text { UV-C } \\
\text { treatments }\end{array}$} & \multicolumn{2}{|c|}{$\mathrm{UAE}$} & \multirow{2}{*}{$\begin{array}{l}\mathrm{LC} \\
\left(\mathrm{mg} \mathrm{g}^{-1}\right)\end{array}$} & \multirow{2}{*}{$\begin{array}{l}\text { TPC } \\
\left(\mathrm{mg} \text { GAE } g^{-1}\right)\end{array}$} & \multirow{2}{*}{$\begin{array}{l}\text { TEAC } \\
\left(\mu \mathrm{M} \text { TEAC } g^{-1}\right)\end{array}$} & \multirow{2}{*}{$\begin{array}{l}\mathrm{DPPH} \\
\mathrm{EC} 50\left(\mu \mathrm{g} \mathrm{mL}^{-1}\right)\end{array}$} \\
\hline & $\mathrm{t}(\min )$ & C (m:v) & & & & \\
\hline \multirow{9}{*}{$\mathrm{C}$ (control) } & 4 & $1: 10$ & $24.4 \pm 0.8$ & $15.8 \pm 2.2$ & $137.5 \pm 0.4$ & $565.5 \pm 1.3$ \\
\hline & 4 & $1: 20$ & $32.4 \pm 0.8$ & $12.7 \pm 1.6$ & $107.8 \pm 0.6$ & $689.4 \pm 3$ \\
\hline & 4 & $1: 30$ & $31.9 \pm 1$ & $17.1 \pm 1.7$ & $97.5 \pm 1.8$ & $679.9 \pm 1.4$ \\
\hline & 8 & $1: 10$ & $27.7 \pm 1.1$ & $9.8 \pm 0.5$ & $241.3 \pm 1$ & $903.5 \pm 4$ \\
\hline & 8 & $1: 20$ & $25.2 \pm 0.6$ & $36.1 \pm 2.2$ & $128.1 \pm 2.5$ & $632.3 \pm 7.2$ \\
\hline & 8 & $1: 30$ & $17.4 \pm 0.6$ & $14.1 \pm 0.9$ & $105.7 \pm 0.1$ & $688.3 \pm 2.4$ \\
\hline & 12 & $1: 10$ & $21.4 \pm 0.9$ & $15.4 \pm 0.5$ & $107.14 \pm 0.1$ & $668.7 \pm 2.5$ \\
\hline & 12 & $1: 20$ & $14.6 \pm 0.9$ & $16.6 \pm 0.9$ & $106.2 \pm 0.2$ & $515.1 \pm 2.7$ \\
\hline & 12 & $1: 30$ & $19.9 \pm 0.7$ & $9.4 \pm 0.9$ & $144.6 \pm 0.3$ & $424.8 \pm 2.3$ \\
\hline \multirow{9}{*}{$\mathrm{UV1}\left(0.5 \mathrm{~J} / \mathrm{cm}^{2}\right)$} & 4 & $1: 10$ & $147.5 \pm 0.3$ & $41.5 \pm 1.1$ & $258.1 \pm 2.4$ & $471.6 \pm 4.7$ \\
\hline & 4 & $1: 20$ & $132.5 \pm 0.7$ & $22.9 \pm 1.4$ & $194.5 \pm 0.5$ & $712.5 \pm 2.8$ \\
\hline & 4 & $1: 30$ & $146.2 \pm 0.6$ & $23.6 \pm 1.6$ & $147.2 \pm 3.2$ & $401.5 \pm 1.6$ \\
\hline & 8 & $1: 10$ & $143.4 \pm 0.6$ & $16.5 \pm 1.8$ & $137.9 \pm 0.5$ & $530.8 \pm 2.6$ \\
\hline & 8 & $1: 20$ & $168.2 \pm 0.7$ & $24 \pm 1.8$ & $214.8 \pm 1.1$ & $351.4 \pm 4.4$ \\
\hline & 8 & $1: 30$ & $147.1 \pm 0.8$ & $19.5 \pm 0.8$ & $132.5 \pm 0.4$ & $392.8 \pm 2.5$ \\
\hline & 12 & $1: 10$ & $146 \pm 0.9$ & $17.3 \pm 1.3$ & $135.3 \pm 0.6$ & $312.0 \pm 9$ \\
\hline & 12 & $1: 20$ & $162.7 \pm 0.4$ & $18.1 \pm 1.5$ & $198.4 \pm 1$ & $513.7 \pm 1.8$ \\
\hline & 12 & $1: 30$ & $155.4 \pm 0.6$ & $19.4 \pm 1$ & $279.7 \pm 1.3$ & $336.3 \pm 2.2$ \\
\hline \multirow{9}{*}{$\mathrm{UV} 2\left(1.0 \mathrm{~J} / \mathrm{cm}^{2}\right)$} & 4 & $1: 10$ & $139.4 \pm 0.9$ & $22.7 \pm 0.4$ & $268.7 \pm 0.7$ & $511 \pm 2.3$ \\
\hline & 4 & $1: 20$ & $135.4 \pm 0.4$ & $14.7 \pm 0.9$ & $100.6 \pm 0.2$ & $655 \pm 4$ \\
\hline & 4 & $1: 30$ & $144.3 \pm 0.6$ & $15.9 \pm 0.7$ & $169.9 \pm 0.7$ & $645.9 \pm 3.3$ \\
\hline & 8 & $1: 10$ & $130.5 \pm 0.8$ & $44.4 \pm 1.7$ & $241.9 \pm 0.4$ & $383.1 \pm 2.8$ \\
\hline & 8 & $1: 20$ & $139.9 \pm 0.6$ & $20.3 \pm 1.4$ & $352.2 \pm 2.2$ & $596.9 \pm 5.1$ \\
\hline & 8 & $1: 30$ & $143.6 \pm 0.2$ & $18.7 \pm 0.8$ & $171.4 \pm 0.8$ & $745.5 \pm 4$ \\
\hline & 12 & $1: 10$ & $139.6 \pm 0.1$ & $34.4 \pm 2$ & $218.7 \pm 1.3$ & $550.7 \pm 1.1$ \\
\hline & 12 & $1: 20$ & $138.1 \pm 0.6$ & $31.9 \pm 2.4$ & $94.3 \pm 0.2$ & $586.9 \pm 5.3$ \\
\hline & 12 & $1: 30$ & $139.1 \pm 0.4$ & $15.6 \pm 1$ & $94.7 \pm 0.4$ & $668.0 \pm 1.3$ \\
\hline$* \mathrm{BHT}$ & & & & $465.5 \pm 3.1$ & $1039 \pm 2.2$ & $72.2 \pm 3.5$ \\
\hline
\end{tabular}

Table 3: Fit Statistics for coefficient regression (ANOVA)

\begin{tabular}{lllllll}
\hline Response variables & $\mathrm{R}^{2}$ & $\mathrm{R}^{2}$ Adjusted & $\mathrm{R}^{2}$ Predicted & Adeq. Precision & F-value & $\mathrm{p}$-value \\
\hline LC & 0.9926 & 0.9906 & 0.9883 & 54.525 & 449,97 & $<0,0001$ \\
TPC & 0.8796 & 0.8423 & 0.7963 & 16.752 & 23,63 & $<0,0001$ \\
TEAC & 0.8661 & 0.8276 & 0.7783 & 17.433 & 49,83 & $<0,0001$ \\
DPPH & 0.9432 & 0.9243 & 0.9020 & 23.004 & 22,46 & $<0,0001$ \\
\hline
\end{tabular}


$70 \mid$ Lima et al.

tions of our model be real and do not present nothing abnormality.

\subsection{Effects of UV-C light and UAE treatments on the lycopene content}

Equation (2) describes the relationship between the significant independent variables and the lycopene content response. For optimization purposes, the second-order polynomial empirical model is widely accepted (Myers, Montgomery, \& Anderson-Cook, 2016). The factors were coded, and the the p-values were less than 0.0001.

$$
L C=+105.49-30.777 X_{s c}+0.52 X_{U V C} X_{s c}
$$

By performing the ANOVA analysis, the cubic reduction model is significant for $\mathrm{LC}$, with an $\mathrm{F}$ 499.47 and $\mathrm{p}<0.0001$. The regression coefficient of $\mathrm{LC}\left(\mathrm{R}^{2}=0.9926\right)$ showing an optimal fit of the model to the experimental values. In addition, the $\mathrm{R}^{2}$ predicted $\left(\mathrm{R}^{2}=0.9883\right)$ agrees with the $\mathrm{R}^{2}$ coefficient $\left(\mathrm{R}^{2}=0.9906\right)$ (Table 3 ). The extracts from the UV1 and UV2 groups yielded mean lycopene content 5.8 times higher than the extracts from the control (C), as represented in Table 2 and Fig. 1.

This result corroborates the results obtained by Pataro, Sinik, Capitoli, Donsi, and Ferrari (2015) which obtained 5.23 times more LC in the irradiated tomatoes compared to the control, using a dose of $2000 \mathrm{~mJ} \mathrm{~cm}{ }^{-2}$, higher than that used and 60 min irradiation time, (similar to the present study).

The increase in lycopene content in tomato as a function of UV-C light treatment was already observed by other researchers. SegoviaBravo, Guignon, Bermejo-Prada, Sanz, and Otero (2012) reported an increase of 1.2 to 1.8 times in the LC in tomatoes stored at room temperature for 8 days at doses ranging from 0.1 to $1.2 \mathrm{~J} \mathrm{~cm}^{-2}$. Likewise, Liu, Zabaras, Bennett, Aguas, and Woonton (2009) observed an increase in the lycopene content, but from irradiated green tomatoes with a dose of $1.37 \mathrm{~J} \mathrm{~m}^{-2}$, in a storage cycle that lasted 21 days, this increase was only significant from the $15^{\text {th }}$ day on, when compared to untreated tomatoes. Although, in the present work the process conditions and origin of the raw material are different from those used in the literature, the same trend in the results is observed.

The control samples (C) differed significantly among the samples under the extraction conditions studied. The highest content was 32.4 and $31.9 \mathrm{mg} \mathrm{g}^{-1}$ after the $4 \mathrm{~min}$ extraction, at the concentrations of $1: 20$ and $1: 30 \mathrm{~m} \mathrm{v}^{-1}$ solvent, respectively (Table 2 ).

\subsection{Effects of UV-C light and UAE treatments on TPC values}

The phenolic content is related to stress conditions that plants undergo while being processed and radiation, mainly UV light, is one of the factors that can influence changes in the amount of this compound in certain vegetable species (Reay \& Lancaster, 2001). Another factor is the temperature control of UAE, taking into account that low extraction temperatures lead to higher yields of secondary metabolites such as as phenolics compounds (Ma, Chen, Liu, \& Ye, 2009). Mathematical model (Eq. 3) correlates total phenolic content (TPC) with process variables in terms of coded factors excluding non-significant terms, with the ratio represented by ANOVA with $\mathrm{R}^{2}=0.8796$ (Table 3 ), where the $\mathrm{p}$-value was less than 0.0001:

$$
\begin{aligned}
& T P C=+19.62-3.59 X_{E T}-4.79 X_{S C} \\
& -5.54 X_{U V C} X_{S C}+4.85 X_{E T} X_{S C} \\
& +3.03 X_{U V C} X_{E T} X_{S C}+7.01 X_{U V C}^{2} X_{S C}
\end{aligned}
$$

TPC content of the extracts ranged from 9.4 to

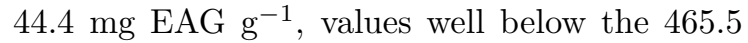
mg EAG $\mathrm{g}^{-1}$ obtained for the synthetic antioxidant BHT, which differed significantly from all extracts $(\mathrm{P}<0.05)$ (Table 2$)$.

Among the samples from tomatoes treated with $\mathrm{UV}-\mathrm{C}$ radiation there was no significant difference that induced the increase of the TPC content, even when compared to the control (C) extracts. This result shows that $\mathrm{UV}-\mathrm{C}$ radiation, in the doses used, did not induce large accumulation of phenolic compounds in the samples. Among the extraction conditions evaluated, the 
best results obtained were for conditions with lower ethanol concentration (1:10) combined with extraction times of 4 and 8 minutes, as shown (Fig. 2). The choice of ethanol as the solvent, was based on the results of previous studies, in which ethanol was the one that presented the best results among many solvents used to extract phenolic compounds from vegetable matrices, which is associated with its polar characteristic (Biscaia \& Ferreira, 2009). Also, the intermiscibility theory states that phenolic compounds are easily dissolved from plant cells when there is similarity between phenolic and solvent polarities (Majeed et al., 2016).

The results obtained for TPC emphasize that the use of lower solvent concentrations and reduced and moderate extraction times, lead to more favorable results for phenolic compounds. This behavior partially corroborates results obtained by Feng et al. (2015), who observed increased phenolic extraction with increasing solvent concentration at the beginning of extraction but noted the inverse behavior when the rate of phenolic extraction reached a certain value, considering that at this moment the polarity of the solvent was inverted, and the extraction started to decrease.

In general, the exposure time is the main factor may have contributed to different results in relation to those found in the literature, but the tomato variety, harvesting and storage conditions, equipment type, arrangement of the fruits during the irradiation and the maturation differences are considerable factors. The time of 60 minutes may not have been enough for the UV-C light to induce a stress response of the fruits that provoked the activation of the phenolic biosynthesis pathway, leading to the accumulation of phenolic compounds, as well as the low UV-C radiation doses used.

\subsection{Response surface analysis of TEAC and effects of UV-C radiation and $\mathrm{UAE}$}

The second-order polynomial model correlating TEAC and the three variables in this study was obtained in Eq. 4, excluding non-significant terms, below:

$$
\begin{aligned}
& T E A C=+148.81-27.70 X_{E T}+29.1 X_{S C} \\
& +23.33 X_{U V C} X_{E T}+21.24 X_{E T} X_{S C} \\
& +30.21 X_{U V C} X_{E T} X_{S C}+6.87 X_{U V C}^{2} X_{S C} \\
& -61.32 X_{E T}^{2} X_{S C}
\end{aligned}
$$

The statistical significance of the model was checked by the F-test where the model F-value of 22.46 implied that the model to be significant $(\mathrm{p}<0.0001)$. The regression coefficient $\left(\mathrm{R}^{2}=\right.$ 0.8661 ) of the experimental model also indicated the model suggested to be a good fit for combining the UV-C and UAE technologies in the antioxidant compounds extraction and showed an acceptable relation with the predicted value $\left(\mathrm{R}^{2}\right.$ $=0.7783)$ (Table 3).

UV-C treatment $(\mathrm{p}<0.0001)$ and solvent concentration $(\mathrm{p}<0.0001)$ had a significant effect on the antioxidant activity, as well as its interactive effects. The extraction time $(\mathrm{p}=0.0317)$ as well as its interactive terms had no significant effect on antioxidant activity by the TEAC method.

From the observation of results (Table 2), none of the UV-C treatments combined with the UAE yielded better results better results than the obtained for the synthetic compound BHT (1039 $\mu \mathrm{M}$ TEAC $\left.\mathrm{g}^{-1}\right)$. However, the treatment with UV-C positively influenced the extracts of the UV1 and UV2 groups, not being significantly different from each other, but with a significant difference in relation to the control $(\mathrm{C})$ samples (Fig. 3).

Low radiation doses can promote a significant increase in antioxidant activity in postharvest tomatoes, agreeing with Ribeiro, Canada, and Alvarenga (2012), as low doses of UV-C radiation $\left(<1000 \mathrm{~mJ} \mathrm{~cm}^{-2}\right)$ promote the formation and increase the bioactive compounds with antioxidant functions, increasing the nutritional value of the treated products.

Samples extracted at times (4 and $8 \mathrm{~min}$ ) and concentrations $\left(1: 10\right.$ and $\left.1: 20 \mathrm{~m} \mathrm{~V}^{-1}\right)$, in the 3 groups, presented AA significantly higher than the other extracts. These results characterize a favorable behavior of the extraction conditions in relation to the antioxidant activity. 
$72 \mid$ Lima et al.

\section{Lycopene content $(\mathrm{mg} / \mathrm{g})$}

A) Current Factor: UV-C Treatment $=$ Control

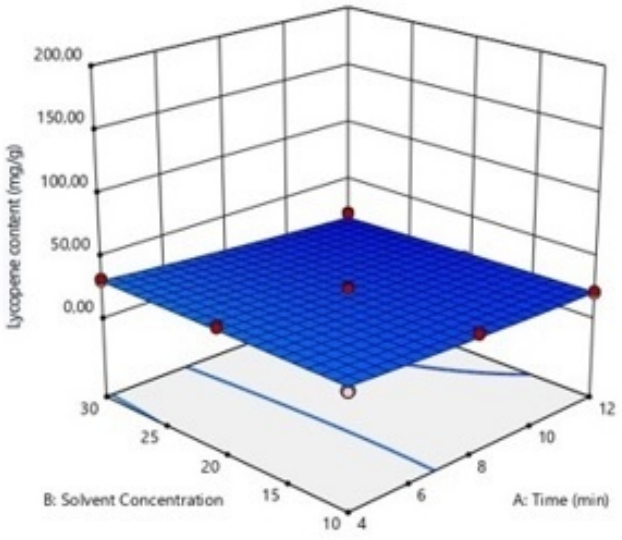

C) Current Factor: UV-C Treatment $=$ UV2

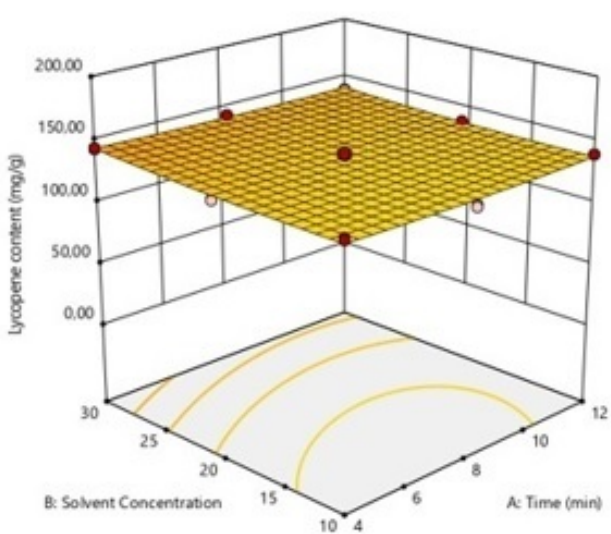

B) Current Factor: UV-C Treatment = UV1

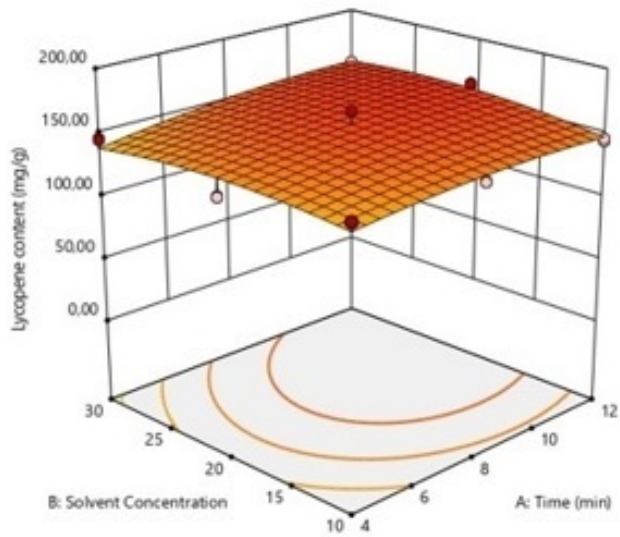

D) Error terms: LC

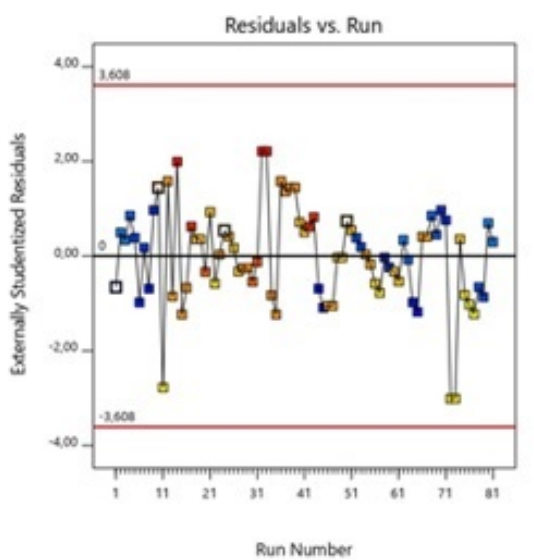

Figure 1: Response surface plots (3D) of LC extraction produced by the polynomial model (eq. 2) (A) UAE; (B) UV-C1 + UAE; (C) UV-C $2+\mathrm{UAE}$; and (D) Analysis of error terms 
Ultrasound-assisted extraction of lycopene extracts from UV-C irradiated cherry tomatoes $\mid 73$

\section{TPC (mgGAE/g)}

A) Current Factor: UV-C Treatment $=$ Control

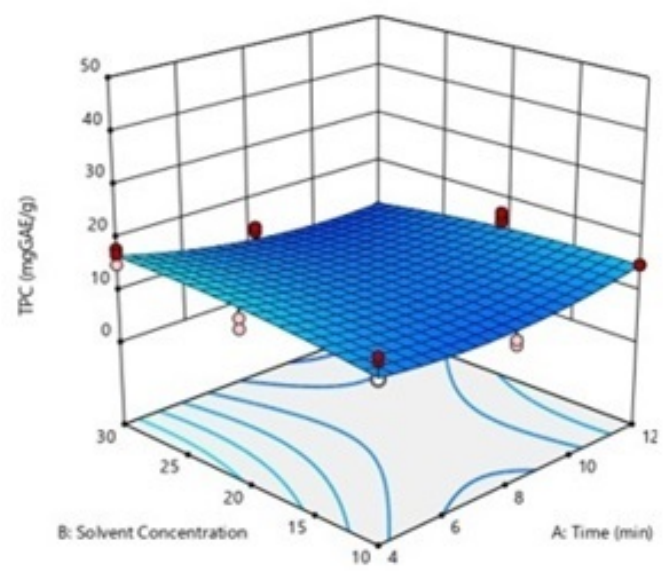

C) Current Factor: UV-C Treatment $=$ UV2

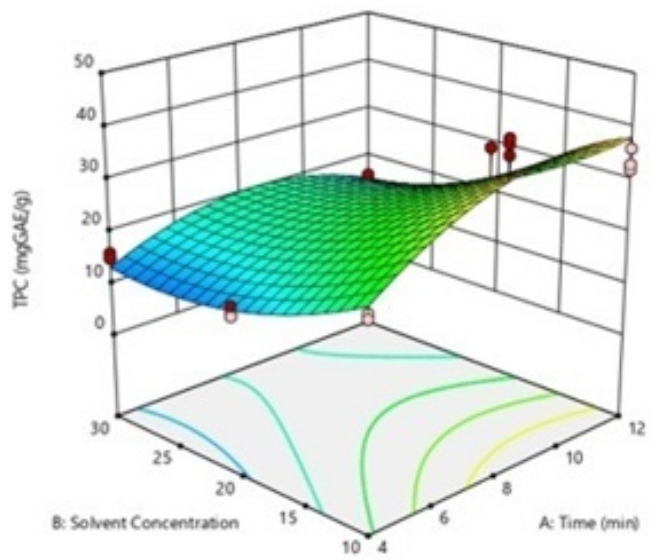

B) Current Factor: UV-C Treatment $=$ UV1

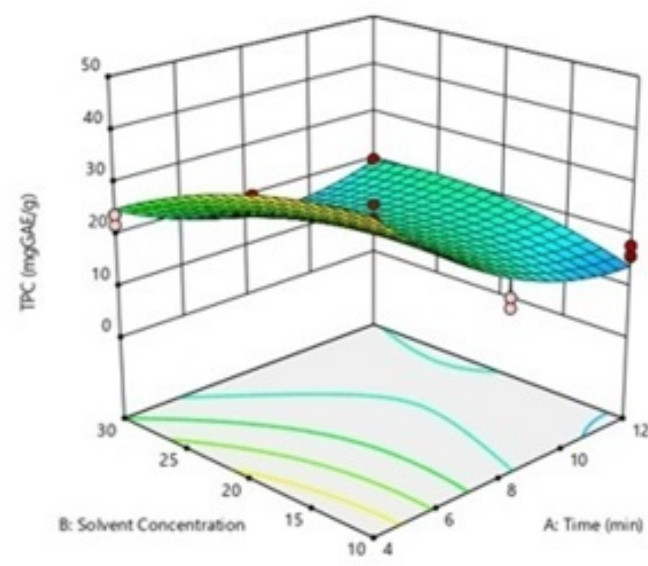

D) Error terms: TPC

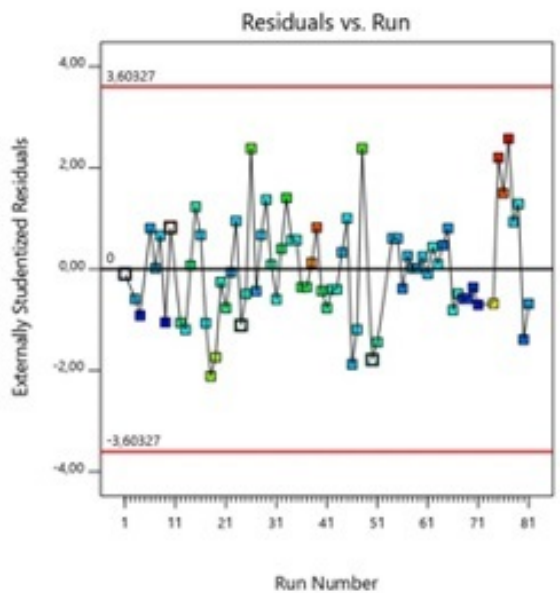

Figure 2: Response surface plots (3D) of TPC analysis as a function of significant interaction between factors; (A) UV-C treatment and time; (B) UV treatment and solvent concentration; (C) time and solvent concentration; (D) Analysis of error terms 
$74 \mid$ Lima et al.

TEAC ( $\mu \mathrm{M}$ TEAC/g)

A) Current Factor: UV-C Treatment = Control

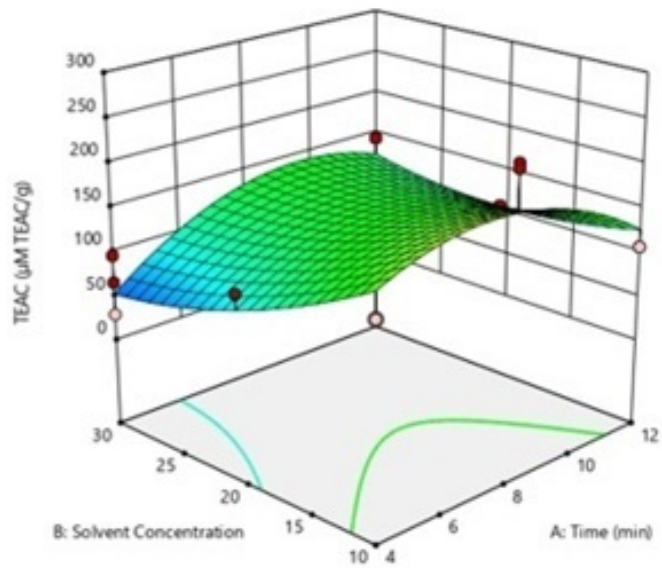

C) Current Factor: UV-C Treatment $=$ UV2

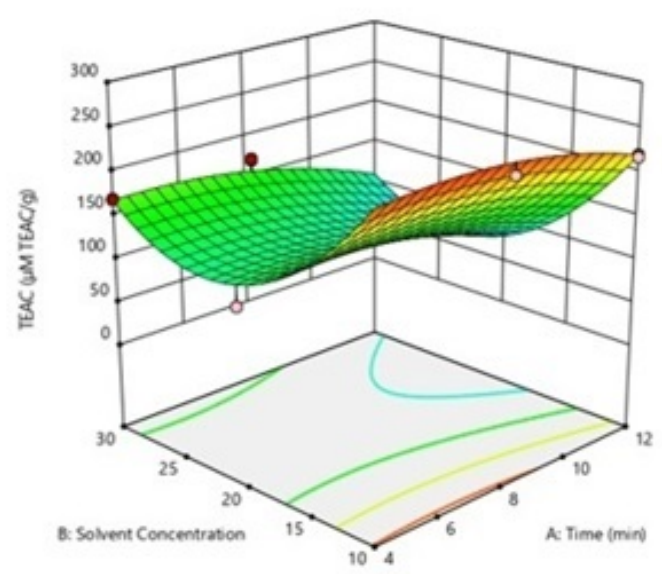

B) Current Factor: UV-C Treatment = UV1

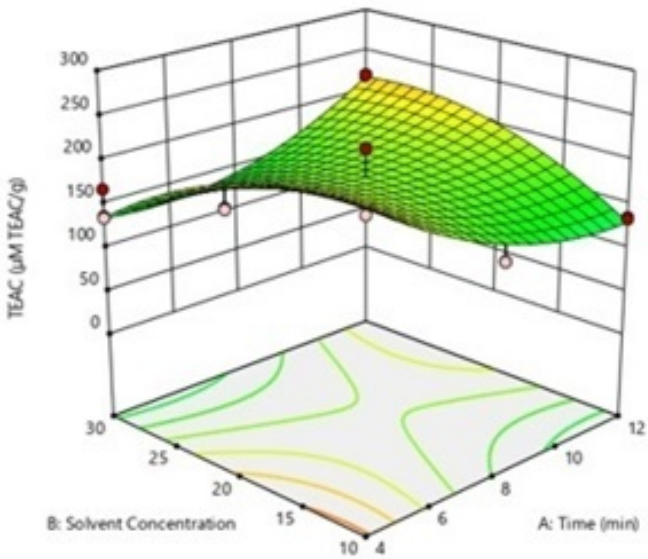

D) Error terms: TEAC

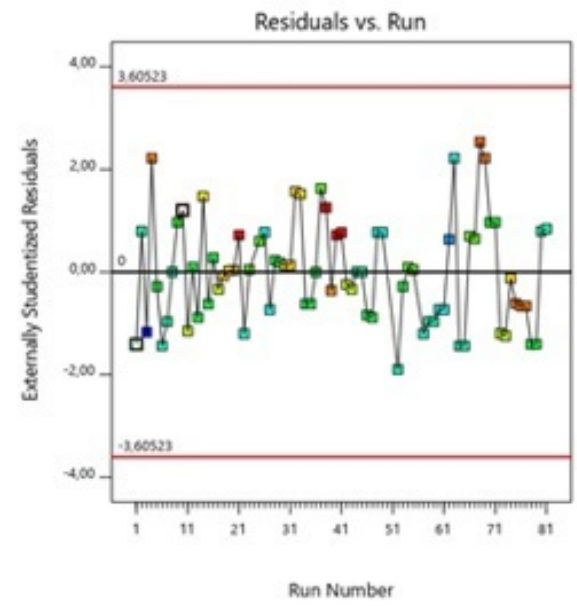

Figure 3: Response surface plots (3D) of antioxidant activity (TEAC analysis) as a function of significant interaction between factors; (A) UV-C treatment and time; (B) UV treatment and solvent concentration; (C) time and solvent concentration; (D) Analysis of error terms 


\subsection{Effects of UV-C radiation and UAE on AA by DPPH method and RSM}

The AA results of the cherry tomato extracts obtained by the DPPH radical capture method are shown in (Table 2) and compared to the result found for the synthetic antioxidant BHT of 72.2 $\mu \mathrm{g} \mathrm{mL}{ }^{-1}$.

The mathematical model Eq. 5 demonstrates the relationship among the DPPH scavenging activity and significant independent variables. For the model fitted, the sample variation of $94.32 \%$ for the DPPH radical scavenging activity was related to the independent variables, and only $5.68 \%$ of the total variation could not be explained by the model (Table 3). p-value was less than $0.0001 \%$ and the model was valid.

Following Eq. 5 represents the coded extraction parameters of the DPPH optimization analysis:

$$
\begin{aligned}
& D P P H=+663.08-42.46 X_{U V C}+107.75 X_{S C} \\
& -23.83 X_{U V C} X_{E T}+15.72 X_{U V C} X_{S C} \\
& -69.04 X_{E T} X_{S C}-103.83 X_{E T}^{2}-18.09 \\
& -X_{U V E} X_{E X} X_{S C}-129.75 X_{U V C}^{2} X_{S C} \\
& -44.58 X_{E T}^{2} X_{S C}
\end{aligned}
$$

$\mathrm{UV}-\mathrm{C}$ radiation was effective in providing an increase in antioxidant activity in the extracted samples. The best DPPH value was obtained in the irradiated samples that were extracted at the moderate and higher times ( 8 and $12 \mathrm{~min}$.), respectively. The ANOVA identified that the solvent concentration (SC) of UAE was not significant (p-value $<0.0001 \%$ ) for TEAC of the samples (Fig. 4).

The treatments with UV-C of the UV1 group $\left(593 \mathrm{~mJ} \mathrm{~cm}^{-2}\right.$ dose, intensity of $1.5 \mathrm{~W} \mathrm{~m}^{-2}$ ), presented higher AA, with a significant difference $(\mathrm{P}<0.05)$ for the other treatments. The results were above $250 \mu \mathrm{g} \mathrm{mL}^{-1}$, a limit value for materials with high antioxidant potential (de Campos, Leimann, Pedrosa, \& Ferreira, 2008). In general, the low antioxidant capacity found can be attributed mainly to the decrease in the phenolic compounds content (Fig. 2).

The data currently found in literature on the effects of low-dose UV-C treatment on the an- tioxidant potential are not only scarce, but also present contradictory conclusions. However, some studies corroborate the results presented in this research. Liu et al. (2012), Pataro et al. (2015), Segovia-Bravo et al. (2012) observed positive effects of UV-C treatment at low doses on distinct tomatoes varieties and maturation stages after storage period. There was no significant effect of UV-C radiation on AA in tomatoes (Jagadeesh et al., 2011) and mushrooms (Guan, Fan, \& Yan, 2012). These studies are in line with the results obtained in the present study for UV2 treatments (doses of $992 \mathrm{~mJ} \mathrm{~cm}^{-2}$ ) (Table 2). The significantly $(\mathrm{P}<0.05)$ better results obtained for AA were 312.0 and $336.3 \mu \mathrm{g} \mathrm{mL}-1$, after 12-min extraction with solvent concentrations of $1: 10$ and $1: 30 \mathrm{~m} \mathrm{~V}-1$, which were not the best conditions for TPC (Table 2). This indicates that the antioxidant activity of the extracts tested was not directly related to phenolic content. Therefore, it can be concluded that AA depends not only on the presence of the phenolic compounds, but also on other compounds with high antioxidant activity that may have had their bioavailability reduced or impaired due to factors inherent to the experimental conditions.

\subsection{Optimization of the experimental model}

An optimization process was carried out to determine the best conditions for the combination process, which yield the maximum LC extraction, maximum TPC and antioxidant activity (lower TEAC and maximum DPPH). The results are shown in Fig. 5.

The optimal conditions selected were a combination of UV2 treatment with UAE during 8.5 min with a minimum solvent concentration (1:10). Under these conditions the predicted values for all the parameters evaluated are presented in Table 2. Lycopene (135.28 $\left.\mathrm{mg} \mathrm{g}^{-1}\right)$, TPC (38.17 mg GAE $\left.\mathrm{g}^{-1}\right)$, antioxidant activity $(252.6 \mu \mathrm{M}$ TEAC $\mathrm{g}^{-1}$ ) and DPPH radical scavenging activity $\left(425.8 \mu \mathrm{g} \mathrm{g}^{-1}\right)$ were within a $95 \%$ mean confidence interval of the experimental values coinciding with two experimental points used in the model, as summarized above, suggesting a good correlation between observed and predicted val- 
$76 \mid$ Lima et al.

\section{DPPH $(\mathrm{EC} 50 \mu \mathrm{g} / \mathrm{mL})$}

A) Current Factor: UV-C Treatment $=$ Control

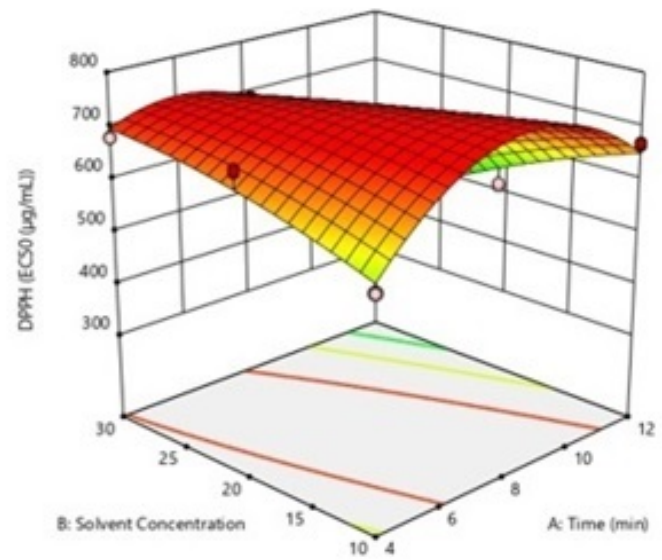

C) Current Factor: UV-C Treatment $=$ UV2

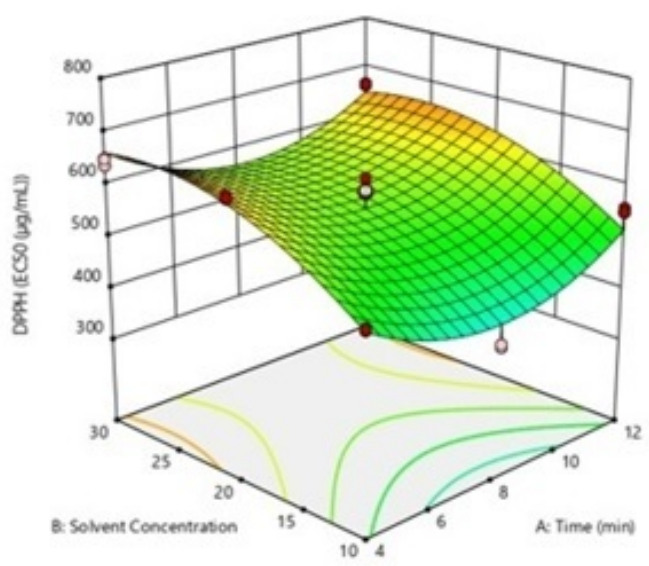

B) Current Factor: UV-C Treatment = UV1

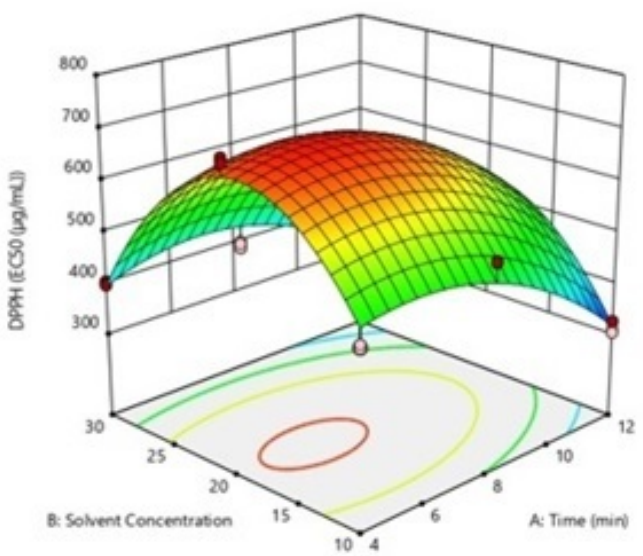

D) Error terms: DPPH

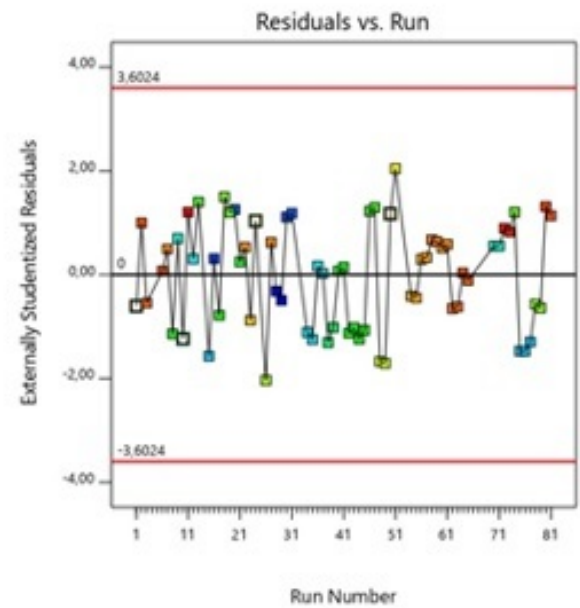

Figure 4: Response surface plots (3D) of total antioxidant activity (DPPH analysis) as a function of significant interaction between factors; (A) UV-C treatment and time; (B) UV treatment and solvent concentration; (C) time and solvent concentration; (D) Analysis of error terms 

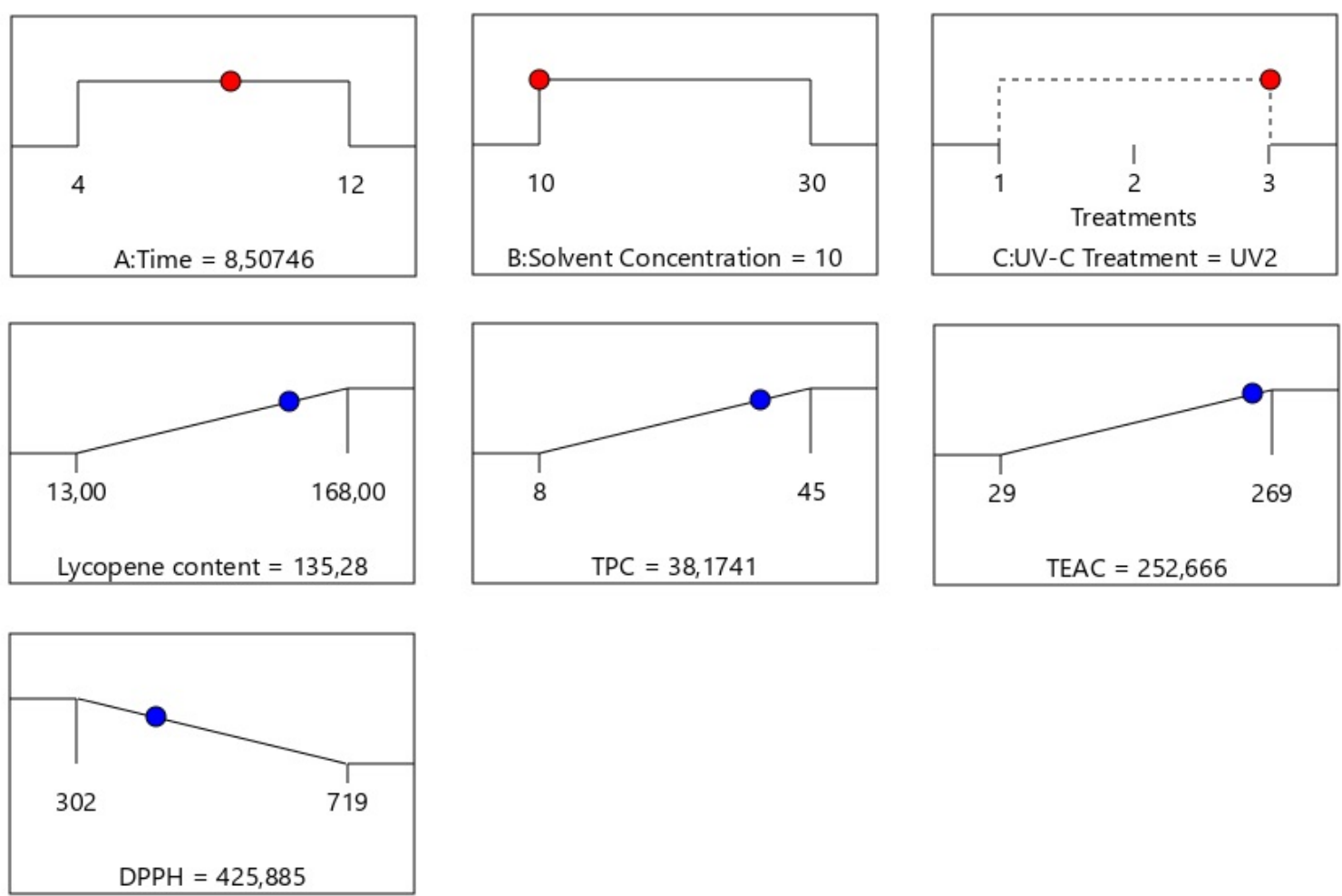

Figure 5: Graphical representation of process optimization

ues.

Based on optimized results it is possible to evaluate the UAE efficiency by observing the low solvent consumption associated with the low extraction time and the easy reproducibility of this technique, demonstrating its high process industrialization potential (Chemat et al., 2017).

In addition to these factors, the good results obtained using ethanol (compounds with antioxidant activity) show that the technology adapts to green solvents, and therefore contributing to environmental impact reduction (Sicaire et al., 2016). These responses are in agreement with Cristofoli, Lima, Vieira, Andrade, and Ferreira (2018) that also obtained consistent results througth UAE with ethanol for compounds with antioxidant activity in another food matrix when compared to other technologies.

\section{Conclusion}

This first attempt to investigate and optimize the combination of UV-C radiation and UAE technologies to obtain cherry tomato extracts ( Lycopersicon esculentum Mill) with high antioxidant bioavailability was effective.

The results obtained suggest strongly that the combination of the UV-C radiation treatment with the UAE process was effective not only in promoting oxidative stress in the raw fruit contributing to the increase of lycopene and the antioxidant content availability in these fruits, but also to help the release of these bioactive compounds from tomato matrix. This study may therefore serve as guidance to industrial extraction processes at environmental temperature and short-time periods by using emerging technologies such as UV-C and ultrasounds promoting the increase of value-added products with a high bioactive compounds index. 


\section{Acknowledgements}

The authors wish to acknowledge $\mathrm{CNPq}$ (National Council of Technological and Scientific Development, Brazil), financial support for research, and the Erasmus Mundus action 2 Fellow Mundus Project for scholarship, the Department of Chemical Engineering and Food Engineering (UFSC - Brazil) and the Department of Food Engineering (UAlg - Portugal) for the opportunity to develop this research.

\section{References}

Artes, F., Gomez, P., Aguayo, E., Escalona, V., \& Artes-Hernandez, F. (2009). Sustainable sanitation techniques for keeping quality and safety of fresh-cut plant commodities. Postharvest Biology and Technology, 51(3), 287-296. doi:10.1016/j.postharvbio. 2008. 10.003

Awad, T. S., Moharram, H. A., Shaltout, O. E., Asker, D., \& Youssef, M. M. (2012). Applications of ultrasound in analysis, processing and quality control of food: A review. Food Research International, 48(2), 410427. doi:10.1016/j.foodres.2012.05.004

Badwaik, L., Prasad, K., \& C. Deka, S. (2012). Optimization of extraction conditions by response surface methodology for preparing partially defatted peanut. International Food Research Journal, 19, 341-346.

Biscaia, D., \& Ferreira, S. R. S. (2009). Propolis extracts obtained by low pressure methods and supercritical fluid extraction. Journal of Supercritical Fluids, 51(1), 17-23. doi:10.1016/j.supflu.2009.07.011

Chemat, F., Rombaut, N., Meullemiestre, A., Turk, M., Perino, S., Fabiano-Tixier, A.-S., \& Abert-Vian, M. (2017). Review of green food processing techniques. preservation, transformation, and extraction. Innovative Food Science 86 Emerging Technologies, 41, 357-377. doi:10.1016/j.ifset.2017.04.016

Chemat, F., Zill-e-Huma, \& Khan, M. K. (2011). Applications of ultrasound in food technology: Processing, preservation and extraction. Ultrasonics Sonochemistry, 18(4, SI), 813-835. 12th Meeting of the
European-Society-of-Sonochemistry, Chania, GREECE, MAY 30-JUN 03, 2010. doi:10.1016/j.ultsonch.2010.11.023

Cristofoli, N., Lima, C. A., Vieira, M., Andrade, K., \& Ferreira, S. (2018). Antioxidant and antimicrobial potential of cajazeira leaves ( spondias mombin ) extracts. Separation Science and Technology, 1-11. doi:10.1080/ 01496395.2018.1508233

de Campos, L. M. A. S., Leimann, F. V., Pedrosa, R. C., \& Ferreira, S. R. S. (2008). Free radical scavenging of grape pomace extracts from cabernet sauvingnon (vitis vinifera). Bioresource Technology, 99(17), 8413-8420. doi:10.1016/j.biortech.2008.02. 058

Di Mascio, P., Kaiser, S., \& Sies, H. (1989). Lycopene as the most efficient biological carotenoid singlet oxygen quencher. Archives of Biochemistry and Biophysics, 274(2), 532-538. doi:10 . 1016 / 0003 9861(89)90467-0

Feng, S., Luo, Z., Tao, B., \& Chen, C. (2015). Ultrasonic-assisted extraction and purification of phenolic compounds from sugarcane (saccharum officinarum l.) rinds. $L W T$ - Food Science and Technology, 60(2, 1), 970-976. doi:10.1016/j.lwt.2014.09.066

Fish, W. W., Perkins-Veazie, P., \& Collins, J. K. (2002). A quantitative assay for lycopene that utilizes reduced volumes of organic solvents. Journal of Food Composition and Analysis, 15(3), 309-317. doi:10.1006/jfca. 2002.1069

Guan, W., Fan, X., \& Yan, R. (2012). Effects of UV-C treatment on inactivation of Escherichia coli O157:H7, microbial loads, and quality of button mushrooms. Postharvest Biology and Technology, 64(1), 119125. doi:10.1016/j.postharvbio.2011.05.017

Honda, M., Watanabe, Y., Murakami, K., Takemura, R., Fukaya, T., Wahyudiono, ... Goto, M. (2017). Thermal isomerization pre-treatment to improve lycopene extraction from tomato pulp. LWT - Food Science and Technology, 86, 69-75. doi:10.1016/j. lwt.2017.07.046

Jagadeesh, S. L., Charles, M. T., Gariepy, Y., Goyette, B., Raghavan, G. S. V., \& Vigneault, C. (2011). Influence of Posthar- 
Ultrasound-assisted extraction of lycopene extracts from UV-C irradiated cherry tomatoes $\mid 79$

vest UV-C Hormesis on the Bioactive Components of Tomato during Post-treatment Handling. Food and Bioprocess Technology, 4 (8), 1463-1472. doi:10.1007/s11947-009$0259-\mathrm{y}$

Karg, M., Pastoriza-Santos, I., RodriguezGonzalez, B., von Klitzing, R., Wellert, S., \& Hellweg, T. (2008). Temperature, $\mathrm{ph}$, and ionic strength induced changes of the swelling behavior of pnipampoly(allylacetic acid) copolymer microgels. Langmuir, 24 (12), 6300-6306. doi:10.1021/ la702996p

Liu, L. H., Zabaras, D., Bennett, L. E., Aguas, P., \& Woonton, B. W. (2009). Effects of uv$\mathrm{c}$, red light and sun light on the carotenoid content and physical qualities of tomatoes during post-harvest storage. Food Chemistry, 115(2), 495-500. doi:10.1016/ j . foodchem.2008.12.042

Liu, Y., Hu, X., Zhao, X., \& Song, H. (2012). Combined effect of high pressure carbon dioxide and mild heat treatment on overall quality parameters of watermelon juice. Innovative Food Science 83 Emerging Technologies, 13, 112-119. doi:10.1016/j.ifset. 2011.11.001

Ma, Y.-Q., Chen, J.-C., Liu, D.-H., \& Ye, X.-Q. (2009). Simultaneous extraction of phenolic compounds of citrus peel extracts: Effect of ultrasound. Ultrasonics Sonochemistry, 16(1), 57-62. doi:10.1016/j.ultsonch.2008. 04.012

Majeed, M., Hussain, A. I., Chatha, S. A. S., Khosa, M. K. K., Kamal, G. M., Kamal, M. A., ... Liu, M. (2016). Optimization protocol for the extraction of antioxidant components from origanum vulgare leaves using response surface methodology. Saudi Journal of Biological Sciences, 23(3), 389396. doi:10.1016/j.sjbs.2015.04.010

Mensor, L. L., Menezes, F. S., Leitao, G. G., Reis, A. S., dos Santos, T. C., Coube, C. S., \& Leitao, S. G. (2001). Screening of brazilian plant extracts for antioxidant activity by the use of dpph free radical method. Phytotherapy Research, 15(2), 127-130. doi:10. 1002/ptr.687

Myers, R. H., Montgomery, D. C., \& AndersonCook, C. (2016). Response surface method- ology: Process and product optimization using designed experiments. 705.

Pataro, G., Sinik, M., Capitoli, M. M., Donsi, G., \& Ferrari, G. (2015). The influence of post-harvest uv-c and pulsed light treatments on quality and antioxidant properties of tomato fruits during storage. Innovative Food Science \&3 Emerging Technologies, 30, 103-111. doi:10.1016/j.ifset.2015. 06.003

Re, R., Pellegrini, N., Proteggente, A., Pannala, A., Yang, M., \& Rice-Evans, C. (1999). Antioxidant activity applying an improved abts radical cation decolorization assay. Free Radical Biology and Medicine, 26 (9-10), 1231-1237. doi:10.1016/S08915849(98)00315-3

Reay, R. F., \& Lancaster, J. E. (2001). Accumulation of anthocyanins and quercetin glycosides in 'gala' and 'royal gala' apple fruit skin with uv-b-visible irradiation: Modifying effects of fruit maturity, fruit side, and temperature. Scientia Horticulturae, 90(12), 57-68.

Ribeiro, C., Canada, J., \& Alvarenga, N. (2012). Prospects of uv radiation for application in postharvest technology. Emirates Journal of Food and Agriculture, 24. doi:10.9755/ ejfa.v24i6.14677

Riera, E., Golas, Y., Blanco, A., Gallego, J. A., Blasco, M., \& Mulet, A. (2004). Mass transfer enhancement in supercritical fluids extraction by means of power ultrasound. Ultrasonics Sonochemistry, 11(3-4), 241244. 4th Conference on the Applications of Power Ultrasound in Physical and Chemical Processing, Besancon, FRANCE, MAY 22-23, 2003. doi:10.1016/j.ultsonch. 2004. 01.019

Segovia-Bravo, K. A., Guignon, B., BermejoPrada, A., Sanz, P. D., \& Otero, L. (2012). Hyperbaric storage at room temperature for food preservation: A study in strawberry juice. Innovative Food Science \& Emerging Technologies, 15, 14-22. doi:10. 1016/j.ifset.2012.02.005

Shi, J., \& Le Maguer, M. (2000). Lycopene in tomatoes: Chemical and physical properties affected by food processing. Critical 
Reviews in Biotechnology, 20(4), 293-334. doi:10.1080/07388550091144212

Sicaire, A.-G., Vian, M. A., Fine, F., Carre, P., Tostain, S., \& Chemat, F. (2016). Ultrasound induced green solvent extraction of oil from oleaginous seeds. Ultrasonics Sonochemistry, 31, 319-329. doi:10.1016/ j.ultsonch.2016.01.011

Singleton, V. L., Orthofer, R., \& LamuelaRaventos, R. M. (1999). Analysis of total phenols and other oxidation substrates and antioxidants by means of folin-ciocalteu reagent. In L. Packer (Ed.), Oxidants and antioxidants, pt a (Vol. 299, pp. 152-178). Methods in Enzymology. 525 B STREET, SUITE 1900, SAN DIEGO, CA 92101-4495 USA: Elsevier Academic Press Inc.

Stevens, C., Khan, V. A., Lu, J. Y., Wilson, C. L., Chalutz, E., Droby, S., ... Tang, A. Y. A. (1999). Induced resistance of sweetpotato to fusarium root rot by uv-c hormesis. Crop Protection, 18(7), 463-470. doi:10.1016/S0261-2194(99)00045-9

Vilkhu, K., Mawson, R., Simons, L., \& Bates, D. (2008). Applications and opportunities for ultrasound assisted extraction in the food industry-a review. Innovative Food Science \&3 Emerging Technologies, $9(2), 161-169$. 3rd Innovative Foods Centre Conference on Food Innovation: Emerging Science, Technologies and Applications, Innovative Foods Ctr, Melbourne, AUSTRALIA, OCT 16-17, 2006. doi:10.1016/j. ifset.2007.04.014 